\title{
Tectônica extensional no cinturão Paraíba do Sul no noroeste do Rio de Janeiro: análise estrutural na seção Itaperuna (RJ) - Muriaé (MG)
}

\author{
Tiago da Rocha Karniol' ${ }^{1}$, Rômulo Machado ${ }^{2}$ \& Leticia Constantino Vicente ${ }^{3}$
}

\begin{abstract}
Resumo Este trabalho descreve a geometria e cinemática de estruturas extensionais e contracionais no cinturão Paraíba do Sul, na porção noroeste do estado do Rio de Janeiro, ao longo da seção Itaperuna (RJ) - Muriaé (MG). Foram reconhecidos três domínios estruturais, onde ocorrem porções mais deformadas contendo zonas de cisalhamento dúcteis de alto ângulo formadas por rochas miloníticas, alternadas por porções, também de alto ângulo, caracterizadas por granulitos e charnockitos com texturas e estruturas mais preservadas da deformação. Em todos os domínios, a foliação principal possui direção NNE-SSW com mergulhos subverticais a intermediários para ESE. Predomina uma lineação de estiramento e mineral subhorizontal e, secundariamente, de mergulho ou com forte obliqüidade. Os indicadores cinemáticos (pares de foliações S-C e S-C-C', estruturas assimétricas, boudins, feldspatos assimétricos etc.) mostram movimentos de topo para SSW (estruturas compressionais) e para ESE (estruturas extensionais). A evolução estrutural da área é interpretada em termos de uma deformação em regime transpressivo com movimentação regional destral, associada a uma partição da deformação devido a condições de contorno (boundary conditions) impostas pela extremidade sul da placa Sanfranciscana durante o evento de convergência oblíqua. As estruturas extensionais apresentadas são relacionadas a um evento extensional anterior ao colapso orogênico (520 a $480 \mathrm{Ma}$ ) descrito para o orógeno Araçuaí e a parte central do cinturão Paraíba do Sul/Ribeira.
\end{abstract}

Palavras-chave: extensional, transpressão parcialmente confinada, cinturão Paraíba do Sul.

\begin{abstract}
Extensional tectonics in the Paraiba do Sul belt, northwestern part of the Rio de Janeiro: structural analyses along the Itaperuna (RJ)-Muriaé (MG) section. This paper describes extensional and contrational structures along the Itaperuna (RJ) - Muriaé (MG) section, northwestern part of Rio de Janeiro State. Three structural domains were described where more deformed portions are characterized by the presence of steeply dipping shear zones with associated mylonitic rocks, and less deformed portions show granulites and charnockites with well-preserved structures and textures. In three structural domains, the foliation runs towards NNE-SSW with sub-vertical and intermediate dip. Stretching lineation is mainly subhorizontal and at some outcrops form downdip structures. Kinematic indicators (S-C and S-C-C' foliations, asymmetric structures, $\sigma$-porphyroclasts, shear-bands and boudins) suggest top-to-SSW shearing and dextral strike-slip component, sub-parallel and oblique to the orogenic trend for the contractional segments and top-to-ESE shearing for the extensional segments. The structural evolution of the area is considered as a result of a regional dextral and partially confined transpression, where strain path partitioning was related to external boundary conditions on the south portion of the Sanfranciscana plate. The extensional event presented in this paper is considered older than the event of the orogenic collapse (520 to $480 \mathrm{Ma}$ ) proposed for the Araçuaí orogen and central portion of the Paraíba do Sul/Ribeira belt.
\end{abstract}

Keywords: extensional, partially confined transpression, Paraíba do Sul belt.

INTRODUÇÃo Estruturas extensionais têm sido descritas em vários cinturões orogênicos do mundo associadas, temporal e espacialmente, a eventos tectônicos compressivos (Coney \& Harms 1984, Wheeler \& Butler 1993, Braathen et al. 2002, dentre outros). Em alguns cinturões orogênicos colisionais modernos como nos Alpes e nos Himalaias, estas estruturas podem ser relacionadas com o transporte lateral de massa no orógeno (Ratschbacher et al. 1991, Pêcher 1991), processo que é favorecido durante a convergência oblíqua de placas, onde a tectônica transpressiva opera desde o início da colisão. Interpretação similar foi proposta recentemente para as estruturas extensionais da região da serra do Azeite na porção sul do cinturão Ribeira, na divisa de São Paulo com o Paraná, sendo sua origem atribuída à extrusão oblíqua relacionada a um regime transpressivo (Dehler et al. 2007).

Recentemente, tem-se reconhecido a importância dos regimes oblíquos, transpressionais e transtrativos, (Holdsworth et al. 1998, Dewey et al. 1988) em diversos cinturões orogênicos modernos e antigos. Por exemplo, no variscano e caledoniano na Europa e na Groenlândia (Holdsworth \& Strachan 1991, Dias \& Ribeiro 1994, LeBlanc et al. 1996, Strachan et al. 2001), 
nos cinturões Arqueanos no Canadá e nos EUA (Hudleston et al. 1988, Borradaille et al. 1993), nos cinturões Neoproterozóicos Dom Feliciano e Ribeira/Paraíba do Sul no sul/sudeste do Brasil (Dayan \& Keller 1989, Ebert \& Hasui 1998, Machado \& Endo 1993 a e b, Fassbinder 1996, Dehler 2002, Egydio-Silva et al. 2002, dentre outros), na província Borborema (Jardim de Sá 1994, Brito-Neves 1999, dentre outros) e no cinturão Mineiro de idade paleoproterozóica (Endo 1997).

Considerando-se um regime transpressivo, tanto durante o evento de convergência oblíqua como na sua fase final (convergência frontal), cabe destacar que os fatores que controlam sua deformação são principalmente as condições de contorno (boundary conditions). Estas envolvem a partição da deformação (no espaço e no tempo), a simetria do fluxo, o nível de profundidade na zona transpressiva, a ordem de nucleação das grandes estruturas e a relação entre as deformações finita e incremental e entre as deformações por cisalhamento simples e por cisalhamento puro (Sanderson \& Marchini 1984, Tikoff \& Teyssier 1994, James \& Watkinson 1994, Robin \& Cruden 1994, Jones et al. 1997).

Desde sua definição original (Harland 1971, Sanderson \& Marchini 1984), que os termos transpressão e transtração têm sido relacionados à convergência e divergência oblíqua de placas tectônicas, onde a deformação envolve a combinação de mecanismos por cisalhamento puro e cisalhamento simples sem variação de volume. A partir de então, o conceito tem se expandido com base em modelos que mostram situações em que o material é impedido de se deslocar em qualquer direção na zona de cisalhamento, sendo então forçado a extrudir verticalmente. Ou mesmo situações em que ele pode se deslocar longitudinal e verticalmente, para baixo e para cima, e em todas as direções, tanto na vertical quanto na horizontal, dando lugar a transpressão não-confinada (Sanderson \& Marchini 1984, Tikoff \& Teyssier 1994, James \& Watkinson 1994, Robin \& Cruden 1994, Jones et al. 1997).

Deve-se ainda ressaltar que esses modelos consideram que o encurtamento perpendicular à zona transpressiva é compensado pelo espessamento vertical, como forma de conservação de volume do segmento transpressivo. Portanto, quando há um encurtamento horizontal, ortogonal ao plano de cisalhamento, há também um estiramento no próprio plano de cisalhamento, que pode ser dominante em uma determinada direção (horizontal, vertical ou oblíqua), formando-se elipsóides prolatos, ou preferencialmente nas direções $\mathrm{X}$ e $\mathrm{Y}$ dos elipsóides de deformação, desenvolvendo-se elipsóides oblatos.

Os dados apresentados sugerem o desenvolvimento contemporâneo de estruturas extensionais e contracionais num segmento da aba norte da divergência estrutural do vale do Rio Paraíba do Sul ao longo de uma seção regional no noroeste do Rio de Janeiro, divisa com Minas Gerais. O regime de deformação, em fácies granulito, foi dominado pela movimentação paralela ao orógeno e as condições de contorno (boundary conditions) a noroeste, devido à presença de uma sali- ência na massa rígida, a Placa Sanfranciscana, foram responsáveis pela partição da deformação no interior do cinturão. Pelo menos num dado momento de sua evolução, o segmento estudado comportou-se conforme um modelo transpressivo confinado parcialmente, isto é, lateralmente e em apenas uma direção, devendo articular-se mais a sul, temporal e espacialmente, com o modelo de transpressão não-confinada, discutido por Dehler et al. 2007.

CONTEXTO TECTÔNICO REGIONAL O lineamento de Além-Paraíba (Almeida et al. 1975, Campanha 1981) ou zona de cisalhamento do Rio Paraíba do Sul (Dayan e Keller 1989) é uma importante feição no Rio de Janeiro que faz parte do arcabouço estrutural do cinturão Paraíba do Sul/faixa Ribeira ou província Mantiqueira Central (Ebert 1968 e 1971, Cordani et al. 1973, Almeida e Hasui 1984). Localiza-se a S-SE do cráton do São Francisco e corresponde a uma das estruturas pré-cambrianas mais expressivas do sudeste brasileiro, sendo responsável pelo controle do curso do rio Paraíba do Sul em toda a sua extensão no Rio de Janeiro. Seu traçado retilíneo é realçado em imagens de satélite e aerogeofísicas, porém, próximo à divisa do Rio de Janeiro com o Espírito Santo, na altura do paralelo $-21^{\circ} 30^{\prime}$, mostra uma mudança de direção de NE para NNE ao se conectar com a zona de cisalhamento Guaçuí (Fig. 1).

Este importante corredor de fluxo é composto por um conjunto interligado de zonas de cisalhamento dúcteis de várias ordens, com mergulhos em geral de médio a alto ângulo, mostrando uma disposição geométrica axialmente divergente associada com estruturas-em-flor positivas, cuja evolução é compatível com um regime tectônico transpressivo (Machado \& Endo 1993 a e b). Também denominado de divergência estrutural (Machado 1984), megassinformal (Heilbron et al. 1991) ou megaestrutura-em-flor positiva do Paraíba do Sul (Machado \& Endo 1993 a e b), o lineamento de Além-Paraíba articula-se com várias zonas de cisalhamento com geometria anastomosada, de direção geral NNE e movimentação destral evidenciada por suas características geométricas e cinemáticas (Dayan \& Keller 1989, Campanha 1981, Dehler 2002, Egydio-Silva et al. 2002, Dehler et al. 2006).

Em escala regional, sua geometria pode corresponder a uma banda de cisalhamento C' associada ao componente coaxial do regime transpressivo (EgydioSilva et al. 2002), o qual é reforçado na região pela coexistência de estruturas compressivas e transcorrentes (Dayan \& Keller 1989, Trompette et al. 1993, Vauchez et al. 1994, Egydio-Silva 1996, Ebert \& Hasui 1998, Dehler \& Machado 2002).

Além disso, vários autores têm reconhecido a importância do fluxo tectônico paralelo ao orógeno no cinturão Paraíba do Sul e na faixa Araçuaí (Dehler \& Machado 2002, Karniol \& Machado 2004, Peres et al. 2004, Egydio-Silva et al. 2002, 2005, Dehler et al. 2006), bem como a presença de estruturas extensionais (Endo 1997, Nalini 1997, Dehler et al. 2000, Dehler 


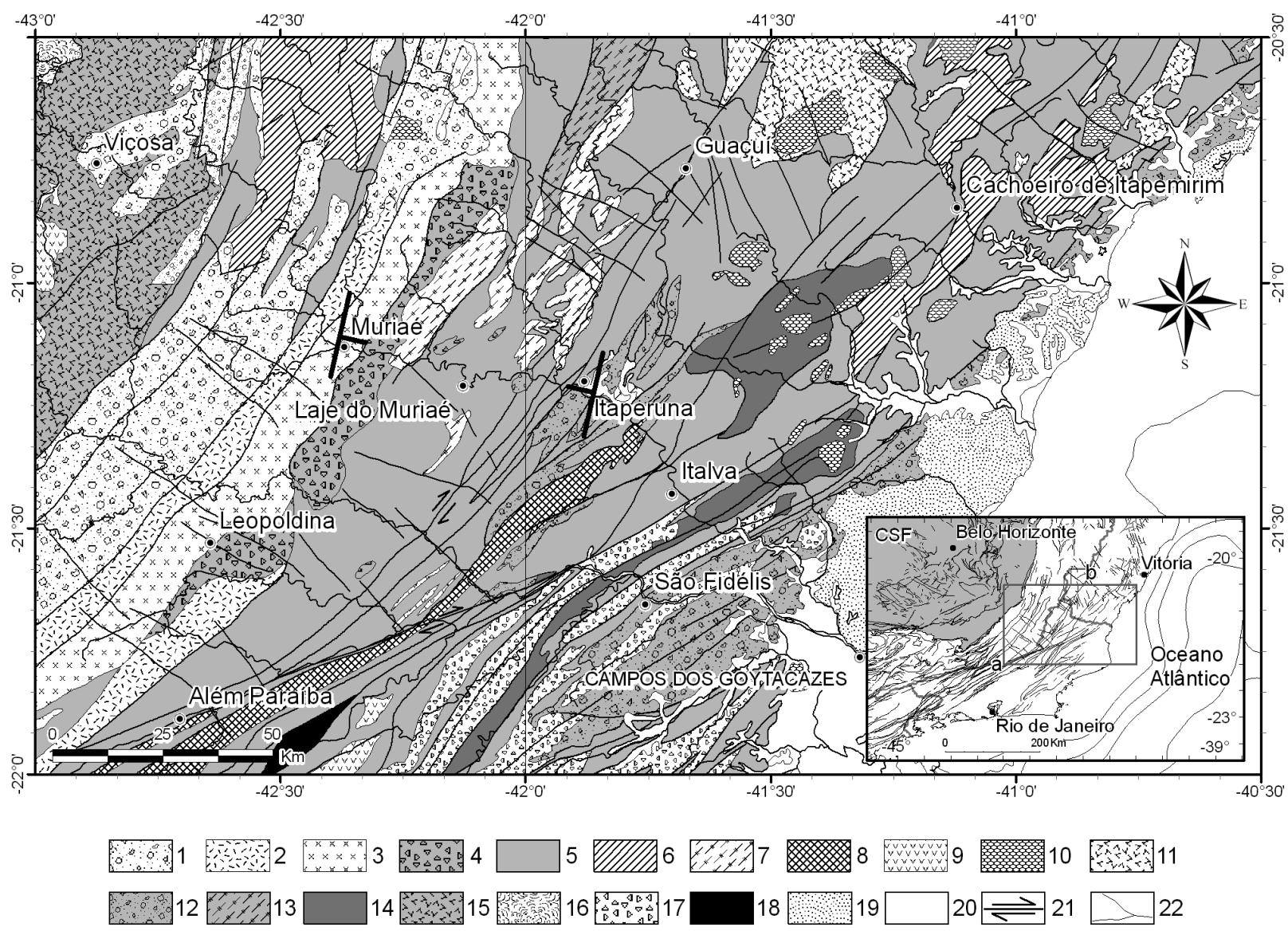

Figura 1 - Mapa geológico da área com a localização do perfil entre Itaperuna (RJ) e Muriaé (MG) (ver Fig. 2). Legenda das unidades: 1- Complexo Juiz de Fora; 2- Suite Quirino; 3- Suite Muriaé; 4- Suite Charnockítica Leopoldina; 5- Complexo Paraiba do Sul; 6- Suite Galiléia, Tonalitos tipo Virginia Velha, Alto Guandu, Bom Jesus do Galho, Cachoeiro; 7- Granitos Eugenópolis, Varre-Sai, Suite Natividade; 8- Suite Granitica Serra da Araras; 9- Granitos Serra do Paquequer, Diorito Concórdia, Granitos e Charnockitos indivisos; 10- Granitos Morro do Coco, Itaoca, Maciços Santa Angélica, Alto Chapéu, Castelo, Rio Novo do Sul; 11- Suite Muniz Freire; 12- Suite Bela Joana; 13- Suite Caparaó; 14- Suite Angelim; 15- Piedade; 16- Dom Silvério; 17- Desengano; 18- Rio Negro; 19- Grupo Barreiras; 20- Depósitos quaternários; 21- Zonas de cisalhamento; 22- Rios. A figura menor (abaixo à direita) mostra a localização da área e a articulação regional entre as principais estruturas e o Cráton do São Francisco (CSF, em cinza), destacando-se o lineamento de Além Paraiba (a) e a zona de cisalhamento Guaçui (b). Fonte: CPRM Serviço Geológico do Brasil - Mapa Geológico do Brasil ao Milionésimo, folhas Rio de Janeiro e Vitória (SF23/SF24).

2002, Dehler \& Machado 2002, Karniol \& Machado 2004, Dehler et al. 2006, Marshak et al. 2006, dentre outros), de forma similar ao que tem sido descrito na literatura internacional (Jarrard 1986, Ratschbacher et al. 1991, Bird 1991, Chauvet \& Séranne 1994, Lyberis \& Mamby 1999, Avigad et al. 2001, Harz et al. 2001, Seyferth \& Henk 2004).

A influência do cráton do São Francisco como um bloco rígido no orógeno foi proposta para explicar o padrão de deformação do cinturão entre os setores meridional e setentrional (Trompette et al. 1993, Vauchez et al. 1994). Neste modelo, a deformação passaria de um domínio tectônico compressivo, contra o cráton, para um domínio transcorrente, no qual as zonas de cisalhamento direcionais possibilitaram o escape lateral de material na direção SW do orógeno. Neste modelo, o escape tectônico seria um mecanismo eficiente para acomodar a deformação do orógeno numa fase tardia da convergência frontal, de forma semelhante ao que ocorre nos Himalaias.

Os dados isotópicos disponíveis sobre esse trecho do cinturão sugerem retrabalhamento crustal durante o ciclo Brasiliano a partir de um embasamento de idade transamazônica (Cordani et al. 1973, Söllner et al. 1991, Machado et al. 1996, Silva et al. 2005).

MATERIAIS E MÉTODOS Para as atividades de campo foram utilizados os materiais convencionais de mapeamento geológico, tais como martelo, lupa, bússola, caderneta de campo, cartas topográficas, imagens de satélite, mapas geológicos, câmara fotográfica digital e GPS - Sistema de Posicionamento Global por Satélite, com projeção Universal Transversa de Mercator (UTM) e datum da América do Sul (SAD-1969).

Durante a realização da seção geológica transversal às estruturas, foi efetuada a análise geométrica das feições planares e lineares, juntamente com a descrição e hierarquização das estruturas tectônicas da 
forma clássica, como descrito em Hobbs et al. (1976). Paralelamente foi realizada a análise cinemática das estruturas, observadas segundo planos XZ do elipsóide de deformação finita, baseado em critérios como lineações de estiramento e mineral, lineação de intersecção e pares de foliações S-C e S-C-C', visando determinar o sentido de rotação do fluxo a partir da interpretação do giro das estruturas assimétricas. As questões envolvidas com esse tema encontram-se sumarizadas em diversos trabalhos e livros de síntese como Simpson \& Schmid (1983), Lister \& Williams (1983), Hanmer \& Passchier (1991), Passchier \& Trouw (1996), dentre outros.

Foram ainda realizadas coletas de amostras orientadas para descrições petrográficas e análises microtectônicas, além de amostras sem orientação para atividades complementares como determinações geocronológicas e geotermobarométricas.

Os dados estruturais de campo foram sistematizados em planilhas digitais e, posteriormente, projetados em diagramas do tipo Schmidt-Lambert, com projeção no hemisfério inferior. As imagens de afloramentos e de seções delgadas são orientadas segundo o plano XZ do elipsóide de deformação finita.

\section{GEOMETRIA DAS ESTRUTURAS}

Introdução A seção foi realizada entre as cidades de Itaperuna (RJ) e Muriaé (MG) (Figs. 1 e 2) ao longo da rodovia BR-356 que liga o noroeste do Rio de Janeiro com o leste de Minas Gerais. Possui uma extensão de $65 \mathrm{~km}$ e direção WNW-ESSE, praticamente transversal às estruturas regionais.

A seção levantada engloba rochas de alto grau metamórfico e corpos intrusivos afetados por zonas de cisalhamento dúcteis de médio a alto ângulo. Em boa parte da seção, estas zonas são responsáveis pelo desenvolvimento de rochas miloníticas a partir de granulitos de composição intermediária a ácida. Estas rochas apresentam uma trama planar constituída por ribbons de quartzo e faixas recristalizadas $(0,01-0,5 \mathrm{~mm}) \mathrm{com}$ geometria anastomosada ao redor de porfiroclastos $(0,5-3 \mathrm{~cm})$ de feldspato e quartzo.

Nas porções intermediárias às zonas de cisalhamento dúcteis, que são as zonas de máxima deformação, são encontradas rochas mais preservadas da deformação como charnockitos e granulitos de cor esverdeada ou de caramelo, com uma estrutura em geral mais homogênea, exibindo muitas vezes um bandamento composicional discreto, cuja estrutura planar é realçada pela presença de níveis de minerais máficos centimétricos, ou pela presença, em escala de afloramento, de estruturas planares ou sigmoidais de espessura decimétrica a métrica.

As rochas das porções intermediárias apresentam uma associação mineralógica constituída de plagioclásio, feldspato potássico, quartzo, granada, clino e ortopiroxênio, anfibólio, biotita e ilmenita como minerais principais, e ainda, titanita, apatita, zircão e clorita como minerais acessórios. A textura é inequigranular, fina a média, com porfiroclastos de quartzo, feldspatos antipertíticos, granada, piroxênio e anfibólio, com evidências de deformação intracristalina como extinção ondulante e maclas polissintéticas deformadas. Os cristais são, em geral, estirados, de dimensões milimétricas (1 a $5 \mathrm{~mm}$ ), com bordas corroídas, envolvidos por uma matriz mais fina $(0,01-0,8 \mathrm{~mm})$, equigranular e granoblástica, composta basicamente por quartzo e feldspato, ou ainda minerais máficos como biotita, piroxênio e anfibólio. Nesses domínios, não há evidências de deformação intracristalina e seu arranjo sugere que se tratam de faixas recristalizadas.

São reconhecidos ainda dois grupos de charnockitos: um representado por corpos foliados e controlados pelas zonas de cisalhamentos, normalmente com forma lenticular, dimensões centimétricas a métricas, paralelos à foliação principal, e outro formado por corpos discordantes, claramente intrusivos e tardios em relação ao primeiro grupo. A principal diferença entre eles refere-se à trama, sendo o primeiro foliado e o último com estrutura maciça, cor verde-caramelo típica, textura inequigranular e granulação grossa, constituído por cristais centimétricos de feldspato pertítico associado com minerais máficos, como piroxênios (clino e orto), anfibólio e biotita.

Os dados estruturais da seção levantada foram tratados seguindo a recomendação de domínios de estruturas homogêneas (Turner \& Weiss 1963) descritos a seguir de leste para oeste (Fig. 2).

Domínio Estrutural I Localizado no setor E do perfil, próximo à cidade de Itaperuna, este domínio compreende uma associação de granulitos relacionada às zonas de cisalhamento de alto ângulo que apresentam taxas variadas de milonitização.

É caracterizado pelo predomínio de zonas de cisalhamento dúcteis que conferem um caráter muito deformado às rochas, com trama plano-linear, foliação bem desenvolvida caracterizada por leitos milimétricos ricos em biotita que se alternam com leitos milimétricos a centimétricos quartzo-feldspáticas e ribbons de quartzo. Em seção delgada, observam-se porfiroclastos milimétricos de plagioclásio e quartzo estirados, envolvidos por uma matriz recristalizada com feldspato, quartzo e biotita e segmentados por ribbons de quartzo. A lineação mineral é formada por agregados de quartzo, feldspato e, eventualmente, biotita.

Nas porções intermediárias às zonas de cisalhamento afloram gnaisses e granulitos com ortopiroxênio e, eventualmente, granada e biotita, caracterizados por uma estrutura planar e sigmoidal, formada por bandas milimétricas a centimétricas.

Em projeção estereográfica, os dados de foliação apresentam concentração principal com direção NNE-SSW a NE-SW e mergulho intermediário a alto para ESE a SE, assim como uma concentração secundária com mergulhos intermediários a altos para NNW a WNW (Fig. 3A).

Os dados lineares deste domínio mostram um paralelismo entre a lineação e o eixo das dobras, exibindo caimentos baixos principalmente para NNE a NE, com uma concentração secundária para SSW (Fig. 3B). 


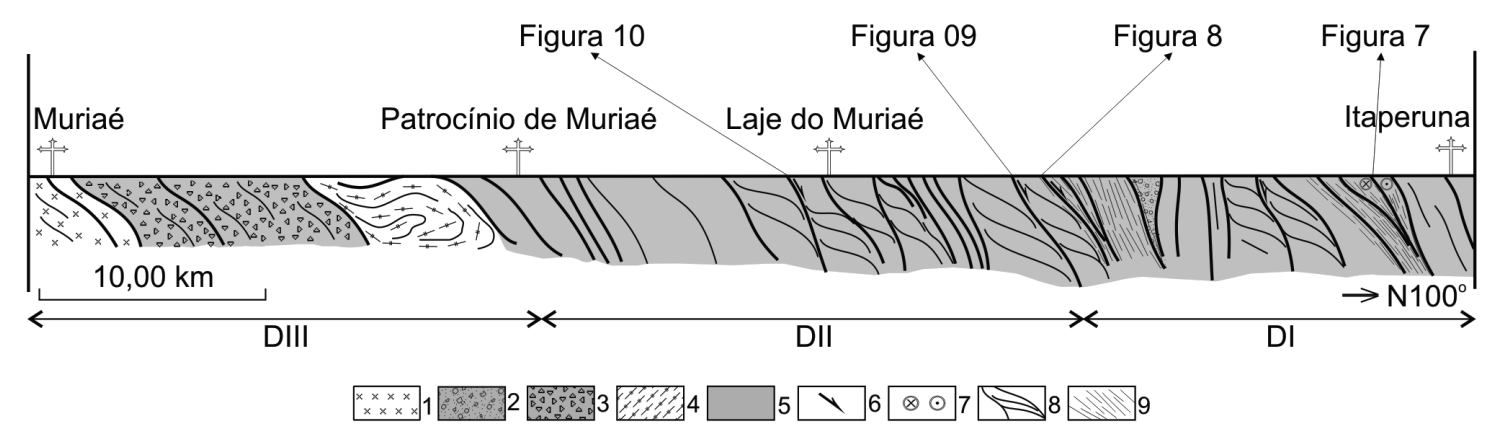

Figura 2 - Perfil geológico entre os municípios de Itaperuna e Muriaé. Legenda: 1- Suite Muriaé; 2- Suite Bela Joana; 3- Suíte Charnockítica Leopoldina; 4- Granito Eugenópolis; 5- Complexo Paraíba do Sul; 6- Sentido de movimentação tectônica; 7- Zonas de cisalhamento destrais; 8- Foliação paralela ao bandamento composicional; 9- Foliação milonítica.

A relação geométrica dessa estrutura com a foliação permite classificá-la como direcional a levemente oblíqua, sugerindo a participação importante do processo de cisalhamento simples no controle dos mecanismos da deformação.

Domínio Estrutural II Este domínio localiza-se nas proximidades de Laje do Muriaé (RJ), onde afloram granulitos, charnockitos e granitos do tipo-S. Nas principais zonas de cisalhamento afloram milonitos com trama planar-linear formada por ribbons de quartzo milimétricos, porfiroclastos de feldspato estirados e boudins de rocha básica, caracterizando uma trama sigmoidal com pares de foliações S-C-C'. Em porções afastadas das zonas de cisalhamento, a foliação torna-se paralela ao bandamento composicional, com bandas máficas e félsicas, centimétricas a decimétricas, exibindo também estruturas sigmoidais assimétricas.

Os dados planares desse domínio, embora apresentem uma relativa dispersão dos pólos, concentramse em planos com direção NNE-SSW e mergulhos intermediários para ESE (Fig. 4A). As concentrações secundárias apresentam direções NE-SW e ENE-WSW, com mergulhos intermediários a altos para SE e NNW.

A lineação é bem desenvolvida neste domínio, principalmente nas zonas de máxima deformação. Caracteriza-se pelo alinhamento de grãos estirados de quartzo, feldspato, biotita e anfibólio, particularmente nas porções com presença de granulitos básicos. Em projeção estereográfica, a lineação apresenta caimento dominantemente intermediário para ESE, com variação de direção entre NE e SE (Fig. 4B). A sua relação geométrica com a foliação principal permite caracterizá-la como uma lineação fortemente oblíqua a de mergulho. Os eixos de dobras apresentam caimento baixo a intermediário para NE.

Domínio Estrutural III Este domínio corresponde ao segmento oeste da seção estudada e situa-se entre os municípios de Patrocínio do Muriaé e Muriaé. Caracteriza-se por uma associação de rochas ortoderivadas pertencentes às suítes
Leopoldina e Muriaé, incluindo ainda o Granito Eugenópolis. A rocha dominante é um charnockito com estrutura dominantemente homogênea, de cor verde-escura, granulação grossa, inequigranular, com textura granoblástica e fenocristais subédricos de plagioclásio de até $5 \mathrm{~cm}$. A foliação é marcada por planos difusos que são mais facilmente observados nas seções XZ do elipsóide de deformação finita.

Alguns afloramentos deste domínio são caracterizados por uma estrutura planar, de espessura decimétrica a métrica associada a bandas de cisalhamento, onde se observa uma lineação mineral pouco desenvolvida, caracterizada pelo alinhamento de cristais milimétricos de plagioclásio, anfibólio e biotita.

Em projeção estereográfica, apesar da relativa dispersão dos pólos da foliação, nota-se um máximo com direção próxima de E-W e mergulhos intermediários para $\mathrm{S}$ (Fig. 5A). Apesar do número relativamente pequeno de lineação, os dados obtidos concentram-se no setor WSW do diagrama e exibem caimentos suaves (Fig. 5B).

ANÁLISE CINEMÁTICA A seção estudada apresenta um quadro cinemático caracterizado pela presença de estruturas compressivas e extensionais, conforme sugerido pela análise cinemática das estruturas assimétricas observadas em cortes orientados segundo o plano XZ do elipsóide de deformação finita.

Os dados estruturais apresentados caracterizam uma estrutura geral planar com orientação NNE-SSW e mergulhos intermediários a altos para ESE (Fig. 6A), associada a lineações (mineral e de estiramento) que apresentam duas orientações principais: uma de caimento baixo para NNE e outra de caimento intermediário para ESE. A primeira pode ser classificada de lineação direcional a levemente oblíqua e a última de fortemente oblíqua a frontal (Fig. 6B). Nota-se ainda um paralelismo entre os eixos de dobras e as lineações direcionais (Fig. 6C).

A intensa deformação associada às zonas de cisalhamento mais expressivas na região foi responsável 
A

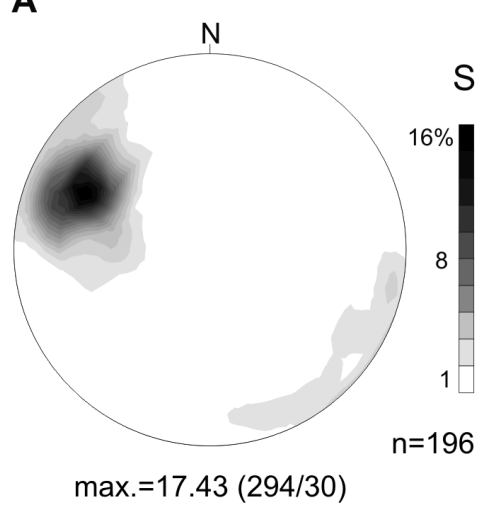

B

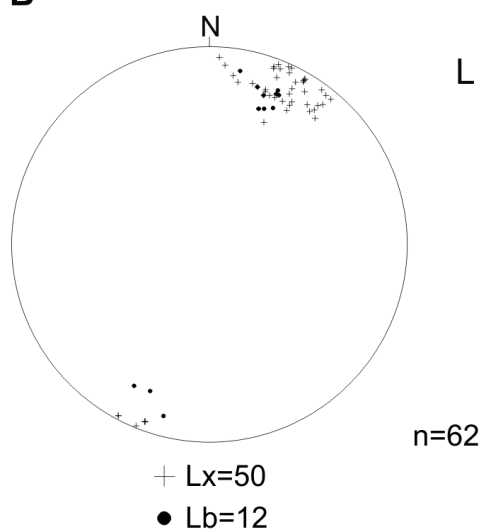

Figura 3 - Dados estruturais do Domínio Estrutural I. A-Pólos de foliação (S); BEstruturas lineares (L): Lx - lineação mineral e de estiramento, Lb - eixo de dobra. Projeção estereográfica em diagrama de igual área de Schmidt-Lambert, hemisfério inferior. Número de dados (n) indicado.

A

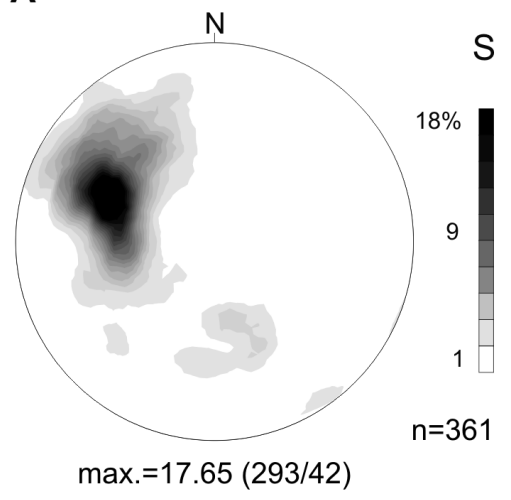

B

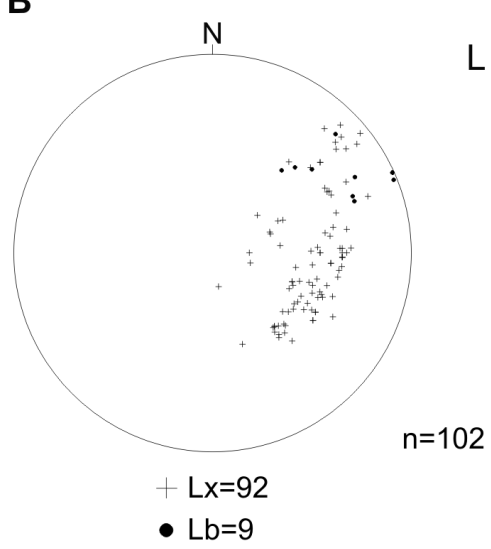

Figura 4 - Dados estruturais do Domínio Estrutural II. A- Pólos de foliação (S); B- Lineação mineral e de estiramento (Lx). Projeção estereográfica em diagrama de igual área de Schmidt-Lambert, hemisfério inferior. Número de dados (n) indicado.

A

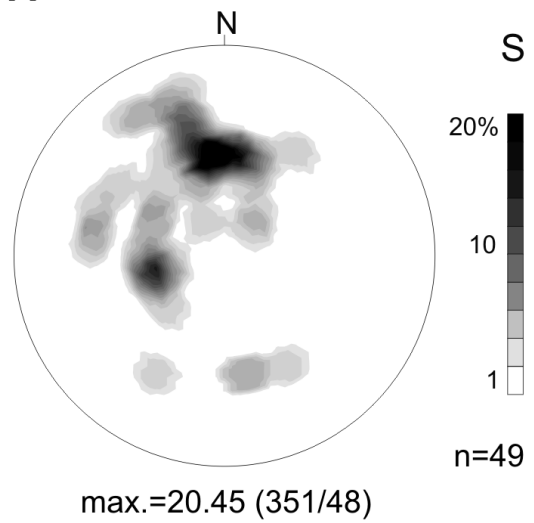

B

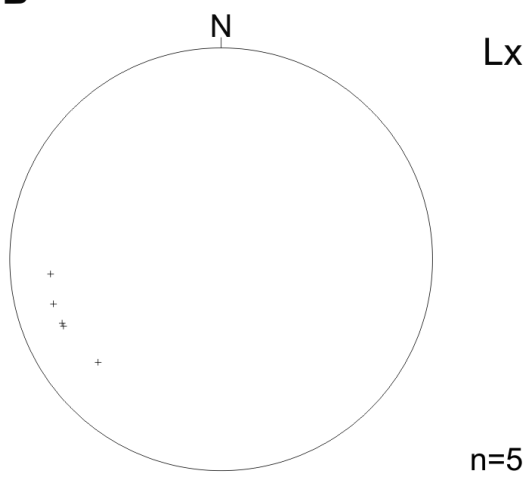

Figura 5 - Dados estruturais do Domínio Estrutural III. A- Pólos da foliação (S), B- Estruturas lineares: Lx - lineação mineral e de estiramento. Projeção estereográfica de igual área de Schmidt-Lambert, hemisfério inferior. Número de dados (n) indicado. 
A

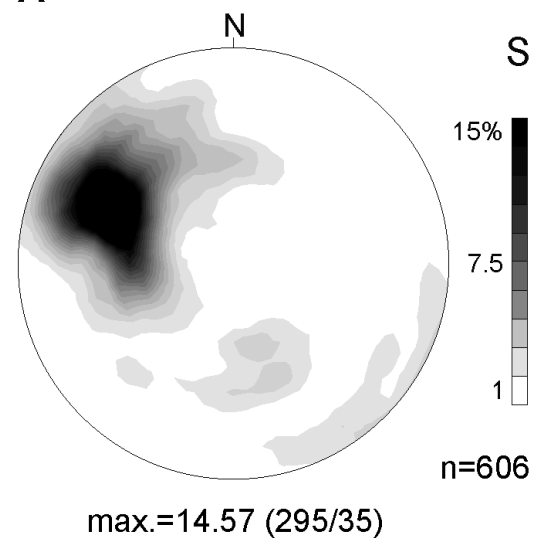

B

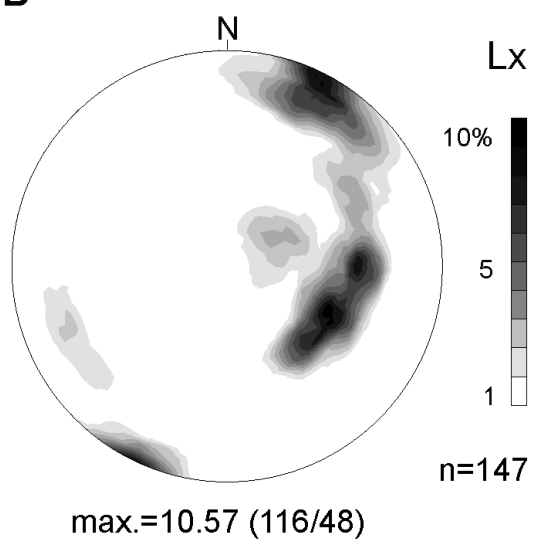

C

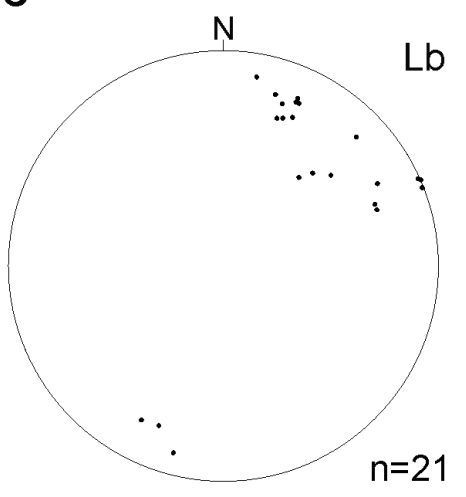

Figura 6 - Dados estruturais de toda a seção. A-Pólos de foliação (S), B-Lineação de estiramento e mineral (Lx); C-Eixos de dobras (Lb). Projeção estereográfica de igual área de Schmidt-Lambert, hemisfério inferior. Número de dados (n) indicado.

A

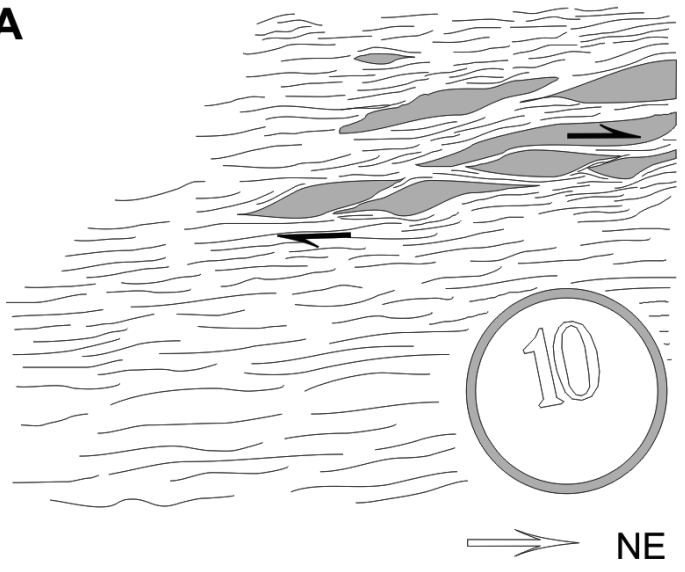

B

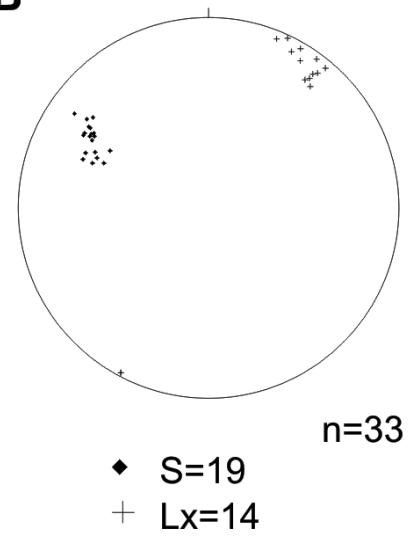

Figura 7 - Zona de cisalhamento direcional destral situada a oeste de Itaperuna. A-Porfiroclastos de quartzo (cinza) com geometria sigmoidal. Corte paralelo ao plano XZ do elipsóide de deformação finita com direção do plano indicada; BProjeção estereográfica dos pólos de foliação $(S)$ e de lineação de estiramento e mineral (Lx). Número de dados ( $n$ ) indicado.

pelo desenvolvimento de uma forte trama planar, que se ressalta nos milonitos e granulitos miloníticos como uma estrutura tipicamente fitada. Em uma das zonas de cisalhamento direcionais de alto ângulo, situada a oeste da Itaperuna, planos S-C-C' de foliações encontram-se associados com porfiroclastos de quartzo com geometria sigmoidal, sugerindo conjuntamente uma movimentação destral (Fig. 7).

Na região próxima à Laje do Muriaé, as zonas de cisalhamento apresentam comportamento cinemático diferenciado. Ao microscópio, a trama fitada das rochas miloníticas é realçada por ribbons de quartzo, semelhante à de outras porções do perfil. Apesar do forte paralelismo exibido pela trama, a geometria dos pares S-C-C' de foliações indica movimentação destral (Fig. 8 ), configurando assim um quadro extensional com mo- vimentação de topo para ESE.

Esta cinemática extensional também é evidenciada junto às paredes de um dique de leucogranito próximo a Laje do Muriaé que promove a deflexão da foliação da rocha encaixante, sugerindo colocação do corpo ao longo de planos C' de foliação (Fig. 9A). Esta relação é reforçada pela presença, no mesmo afloramento, de porfiroclastos de anfibólio estirados, tanto na escala meso (Fig. 9B) quanto microscópica (Fig. 9C). Assim como na figura 8, este afloramento apresenta lineação de mergulho (Fig. 9D).

A oeste de Laje do Muriaé ocorre outro dique de leucogranito em uma zona de cisalhamento (Fig. 10A) em situação tectônica similar, sugerindo igualmente colocação sob condições extensionais. Neste local, corpos leucograníticos lenticulares e sigmoidais (Fig. 10B) es- 
A

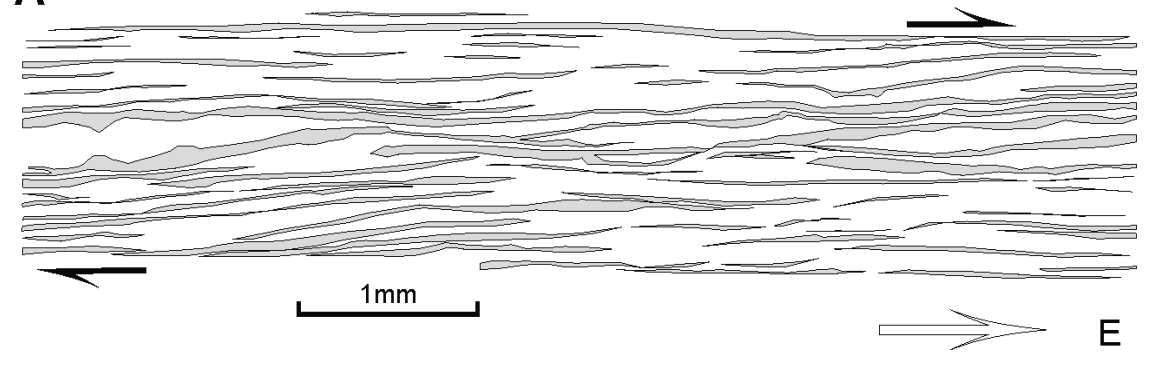

B

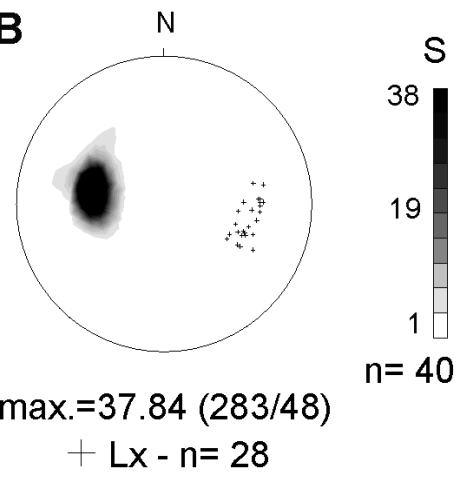

Figura 8 - Seção delgada de milonito em uma zona de cisalhamento extensional próxima de Laje do Muriaé. Corte paralelo ao plano XZ do elipsóide de deformação finita com direção do plano indicada. A-Pares $S$-C-C'de foliações paralelizados, porém com assimetria compativel com cinemática destral, associada a fluxo extensional com movimento de topo para ESE; B-Projeção estereográfica dos pólos de foliação (S) e de lineação de estiramento e mineral (Lx). Número de dados (n) indicado.

A

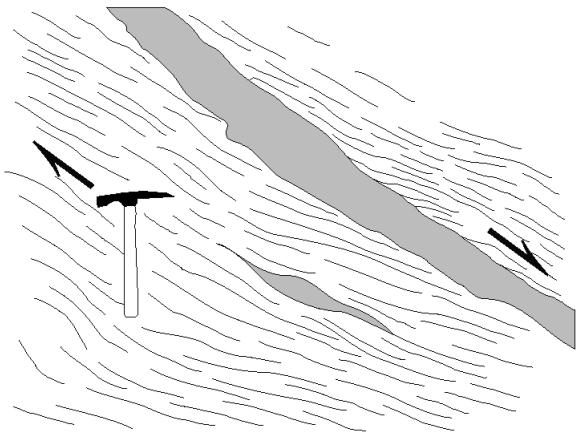

C

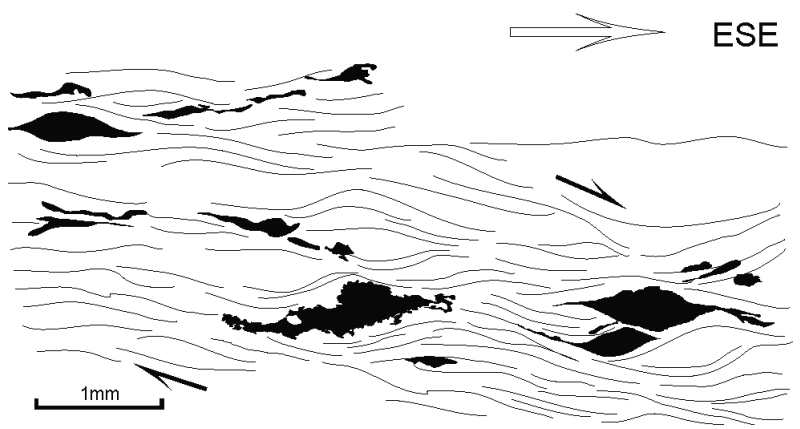

B

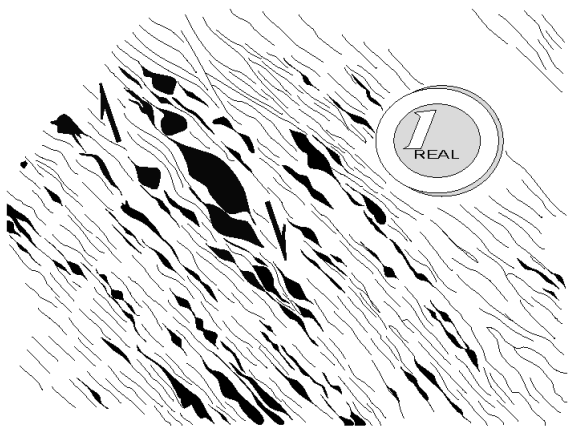

D

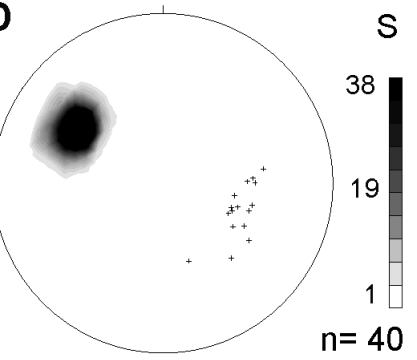

$\max =38.93(293 / 42)$

$+L X-n=18$

Figura 9 - Indicadores cinemáticos coerentes com movimentação relativa destral associados a uma movimentação extensional em localidade próxima de Laje do Muriaé. Corte paralelo ao plano XZ do elipsóide de deformação finita com direção do plano indicada. A-Dique de leucogranito com deflexão da foliação no contato; B-Porfiroclastos centimétricos de anfibólio contornados por bandas de cisalhamento extensionais assimétricas; $C$ - Situação semelhante, mas em escala microscópica; D-Projeção estereográfica dos pólos de foliação $(S)$ e de lineação de estiramento e mineral (Lx). Número de dados (n) indicado.

tão dispostos ao longo de planos C' de foliações e porfiroclastos de feldspato tipo $\delta$ (Fig. 10C) são compatíveis com o regime acima mencionado (Fig. 10D). Em seção delgada observa-se anfibólio ao redor de cristais de ortopiroxênio, além de concentrações relativamente mais elevadas de granada e biotita.
DISCUSSÃO E CONCLUSÕES Em termos regionais, a seção estudada localiza-se num segmento onde as estruturas do cinturão apresentam uma grande curvatura, articuladas, a sul, pelo lineamento de Além-Paraíba (Fig. 1). No campo, evidenciam-se porções menos deformadas onde 
A

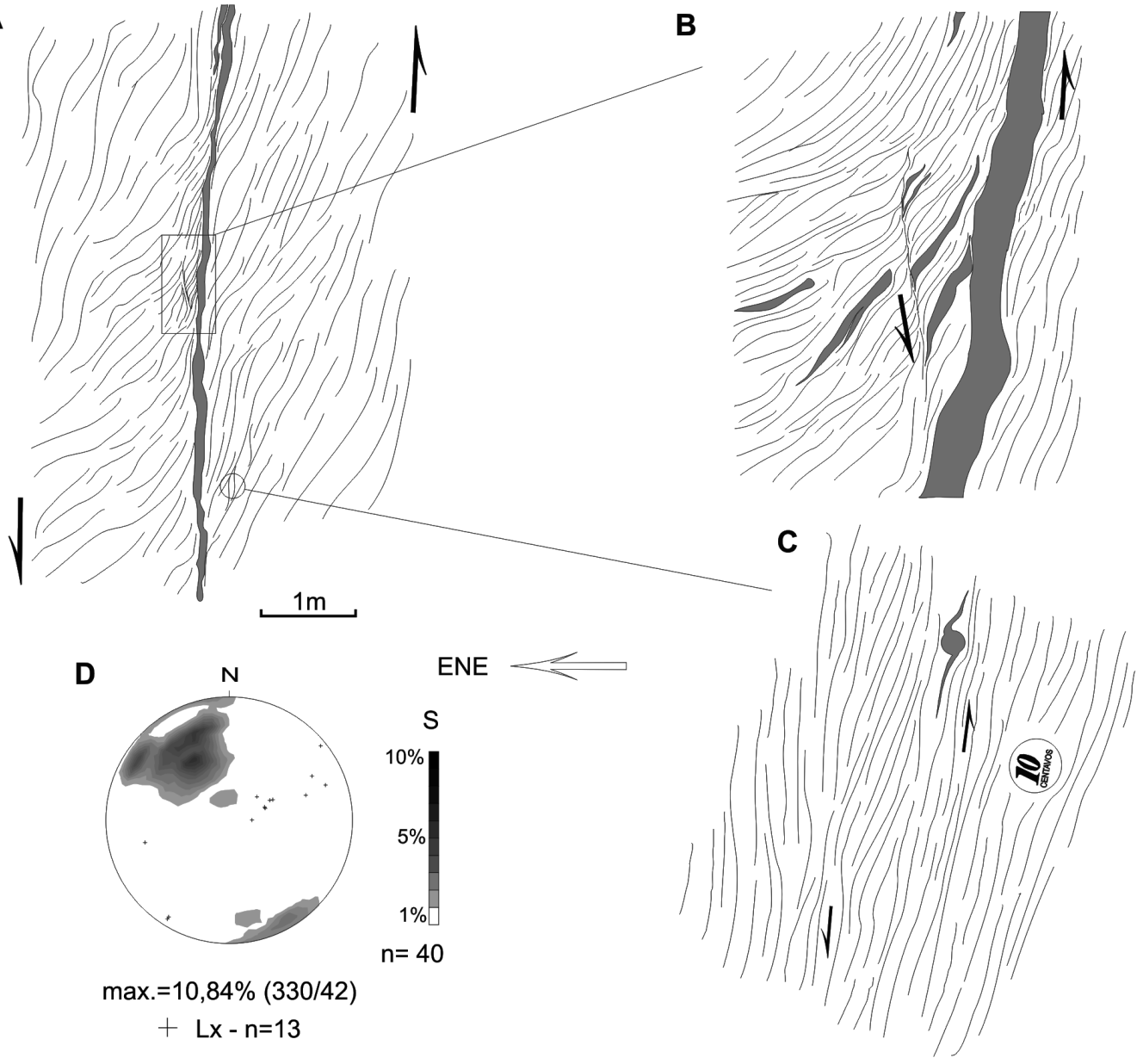

Figura 10 - Indicadores cinemáticos em uma zona de cisalhamento extensional nas imediações de Laje do Muriaé. Cortes paralelos à seção XZ do elipsóide de deformação finita com direção indicada. A-Dique de leucogranito (cinza) ao longo na zona de cisalhamento, com deflexão da foliação nos contatos; B-Detalhe da figura anterior, com lentes sigmoidais paralelas a planos $S$ de foliações; $C$ - Porfiroclasto de feldspato tipo $\delta$; D- Projeção estereográfica dos pólos de foliação $(S)$ e de lineação de estiramento $e$ mineral (Lx). Número de dados (n) indicado.

afloram granulitos, charnockitos e granitos, alternadas por porções mais deformadas, caracterizadas pela presença de zonas de cisalhamento dúcteis geralmente de alto ângulo constituídas por milonitos, gnaisses e granulitos miloníticos. Esta relação pode ser observada em escalas variadas e configura um dos mecanismos de partição da deformação.

Os dados estruturais apresentados evidenciam um quadro tectônico composto. No domínio estrutural I, as zonas de cisalhamento apresentam movimentação direcional destral e caracterizam-se por estruturas de alto ângulo com uma lineação direcional a levemente oblíqua.

Por outro lado, no trecho correspondente ao domínio II, onde a foliação apresenta ângulo intermediário e a lineação caráter oblíquo a de mergulho, predomina uma tectônica extensional com movimentação de topo para ESE. Neste trecho, as assembléias minerais foram formadas sob condições de metamorfismo de alto grau, refletindo estruturas desenvolvidas em nível de crosta inferior, situação ainda não descrita na região norte do estado do Rio de Janeiro.

Numa primeira análise, estes dois grupos cinemáticos de estruturas parecem estar associados a eventos tectônicos distintos. Contudo, os resultados obtidos mostram que eles se desenvolveram em situação reológica similar, sob condições metamórficas compatíveis com nível crustal inferior. Além disso, não foram observadas relações de superposição cinemática de estruturas, o que afasta a possibilidade de haver diferença temporal na geração das mesmas.

Cabe mencionar que as rochas dos domínios com estruturas extensionais apresentam maior proporção de paragêneses hidratadas (principalmente anfibólio e biotita e, eventualmente, granada) do que as rochas dos domínios com estruturas contracionais, indicando a importância do processo de exumação de rochas infracrustais, bem como recristalização metamórfica sob condições de pressões de água mais altas do que nos domínios contracionais. 
Alguns autores têm descrito a existência de uma tectônica extensional em outros segmentos da província Mantiqueira, baseada principalmente na natureza do magmatismo ou ainda na caracterização de estruturas tectônicas desenvolvidas em regime extensional. $\mathrm{O}$ primeiro caso parece corresponder a uma tectônica extensional mais nova, com idade entre 520 a 500-480 $\mathrm{Ma}$, que tem sido descrita no cinturão Paraíba do Sul (Machado 1997, Trouw et al., 2000, Heilbron et al. 2004, dentre outros) e na faixa Araçuaí (Marshak et al. 2006, dentre outros). O segundo pode relacionar-se a uma tectônica extensional mais antiga com movimento de topo para E e ESE, reportada em várias regiões dos cinturões/faixas acima referidos (Nalini 1997, Dehler et al. 2000, Karniol \& Machado 2004, Dehler et al. 2006 e 2007). Um exemplo deste último caso refere-se à região de Cajati, divisa de São Paulo com o Paraná, onde as estruturas extensionais foram desenvolvidas em condições metamórficas compatíveis com a fácies anfibolito, em regime de pressão intermediária e caminho PTt horário (Dehler et al. 2000 e 2007). Neste local são descritas ainda dobras em bainha e dobras sin-miloníticas com eixos paralelos a lineação de estiramento mineral, indicando altos valores de deformação por cisalhamento simples (Dehler et al. 2000).

Sabe-se que em um ambiente transpressivo a exumação do segmento metamórfico pode estar relacionada a uma tectônica de extrusão ou escape lateral (Dias \& Ribeiro 1994, Jones et al. 1997). Esta condição é reconhecida em cinturões deformados antigos e modernos, a exemplo dos Caledonides (Chauvet \& Sérrane 1994, Lyberis \& Mamby 1999), do mar Egeu (Avigad et al. 2001), do Cáucaso, dos Alpes e dos Himalaias (Philip et al. 1989, Mancktelow 1992, Inger 1998) e da província Mantiqueira Central (Trompette et al. 1993, Vauchez et al. 1994, Hackspacher \& Godoy 1999, Dehler 2002).

O modelamento da colisão crustal em duas (Ratschbacher et al. 1991) e em três dimensões (Seyferth \& Henk 2004) revela que há um comportamento complexo da crosta com variações espaciais e temporais relacionadas à partição da deformação em termos do fluxo extensional, compressivo ou direcional. Contudo, os modelos revelam que os movimentos extensionais estão intimamente associados aos processos transpressivos e podem ocorrer desde os estágios iniciais até finais de uma colisão.

Os dados apresentados sugerem o desenvolvimento contemporâneo de estruturas extensionais e contracionais, sob condições metamórficas compatíveis com a fácies granulito, num regime de deformação dominado pela movimentação paralela ao orógeno. A existência de condições de contorno (boundary conditions) a noroeste do orógeno, devido à presença de uma massa rígida (a placa Sanfranciscana), funcionou como elemento indutor na partição da deformação no interior do cinturão, comportando-se, no segmento estudado e pelo menos em um dado momento de sua evolução, como um sistema transpressivo parcialmente confinado (confinamento lateral em apenas uma direção). Para sul, na altura de Três Rios e Paraibuna (RJ), as condições do fluxo tectônico aparentemente aproximam-se do modelo de transpressão não-confinada.

Apesar da ausência no momento de informações geocronológicas sobre as estruturas extensionais caracterizadas neste trabalho, os resultados apresentados sugerem que estas se relacionam a princípio ao evento tectônico extensional mais antigo, como descrito na região de Cajati-SP, e não ao evento mais recente relacionado ao colapso gravitacional tardio do orógeno.

Agradecimentos Os autores agradecem ao Conselho Nacional de Desenvolvimento Científico e Tecnológico (CNPq), pela concessão de uma bolsa de doutorado a T.R.Karniol e de uma bolsa de Produtividade em Pesquisa a R. Machado (Proc. 300423/82-9). Agradecem ainda ao colega Nolan Maia Dehler, pelas proveitosas discussões e sugestões ao artigo, ao Instituto de Geociências da USP, pelas facilidades no uso de vários laboratórios e aos relatores da RBG.

\section{Referências}

Almeida F.F.M, Hasui Y., Carneiro C.D.R. 1975. Lineamento de Além-Paraíba. An. Acad. Bras. Ciênc., 47:575

Almeida F.F.M \& Hasui Y. 1984. O Pré-Cambriano do Brasil. São Paulo, Edgard Blücher, 378 p.

Avigad D., Ziv A., Garfunkel Z. 2001. Ductile and brittle shortening, extension-parallel folds and maintenance of crustal thickness in the central Aegean (Cyclades, Greece). Tectonics, 20:277-287.

Bird P. 1991. Lateral Extrusion of Lower Crust from Under High Topography, in the Isostatic Limit. J. Geoph. Res., 96: $10.275-10.286$.

Borradaile G.J., Werner T., Dehls J.F., Spark R N. 1993. Archean regional transpression and paleomagnetism in northwestern Ontario, Canadá. Tectonophysics, 220:117125.

Braathen A., Osmundsen P.T., Nordgulen Ø., Roberts D.,
Meyer G.B. 2002. Orogen-parallel extension of the Caledonides in northern Central Norway: an overview. Norw. Jour. Geol., 82:225-241.

Brito-Neves B. B. 1999. The Cambro-Ordovician of the Borborema Province. Geol. USP Ser. Cient., 29:175-193.

Campanha G.A.C. 1981. O lineamento Além Paraíba na área de Três Rios (RJ), Rev. Bras. Geoc., 11:159-171.

Chauvet A. \& Séranne M. 1994. Extension-parallel folding in the Scandinavian Caledonides: implications for lateorogenic processes. Tectonophysics, 238:31-54.

Coney P.J. \& Harms T.A. 1984. Cordilleran metamorphic core complexes: Cenozoic extensional relicts of Mesozoic compression. Geology, 12:550-554.

Cordani U.G., Delhal J., Ledent D. 1973. Orogéneses superposées dans Ia précambrien du Brésil Sud-oriental (Etats de Rio de Janeiro et Minas Gerais). Rev. Bras. Geoc., 
3:1-22.

Dayan H. \& Keller J.V.A. 1989. A zona de cisalhamento do Rio Paraíba do Sul nas vizinhanças de Três Rios (RJ): uma análise da deformação dada por algumas feições estruturais. Rev. Bras. Geoc., 19:494-506.

Dehler N.M, Machado R., Dehler H., McReath I., Nummer A. 2006. Kinematics and geometry of structures in the southern limb of the Paraíba do Sul divergent structural fan, SE Brazil: a true transtensional shear. An. Acad. Bras. Ciênc., 78:1-17.

Dehler N.M. \& Machado R. 2002. Geometria e cinemática da aba sul da estrutura divergente do Rio Paraíba do Sul ao longo da seção Area-Três Rios, Rio de Janeiro. Rev. Bras. Geoc., 32:481-490.

Dehler N.M. 2002. Extrusão tectônica oblíqua em regime transpressivo no Cinturão Paraibides, RJ. São Paulo, Tese de Doutoramento, Univ. de São Paulo, 170 p.

Dehler N.M., Machado R., Vasconcelos C.S. 2000. Tectônica extensional oblíqua no sul do estado de São Paulo. Rev. Bras. Geoc., 30:699-706.

Dehler N.M, Rômulo M., Fassbinder E. 2007. Shear structures in the Serra do Azeite shear zone, southeastern Brazil: Transtensional deformation during regional transpression in the central Mantiqueira province (Ribeira belt). J. South Am. Earth Sci., 23:176-192.

Dewey J.F. 1988. Extensional collapse of orogens. Tectonics, 7:1123-1139.

Dias R. \& Ribeiro A. 1994. Constriction in a transpressive regime: an example in the Iberian branch of the IberoArmorican arc. J. Struc. Geol., 16:1543-1554.

Ebert H. 1968. Ocorrências de fácies granulíticas no sul de Minas Gerais e em áreas adjacentes em dependência da estrutura orogênica: hipóteses sobre sua origem. An. Acad. Bras. Ciênc., 40:215-229.

Ebert H. 1971. Os Paraibides entre São João Del Rey, Minas Gerais e Itapira, São Paulo, e a bifurcação entre Paraibides e Araxaídes. In: SBG, Congr. Bras. Geol., 25, Bol. Especial, p. 177-178.

Ebert H. D. \& Hasui Y. 1998. Transpressional tectonics and strain partitioning during oblique colision between three plates in the precambrian of south-east Brazil. In: R.E. Holdsworth, R.A. Strachan, J.F. Dewey (eds.) Continental transpressional and transtensional tectonics. London, Spec. Publ. Geol. Soc., 135, p.231-252.

Egydio-Silva M. 1996. Zona de cisalhamento de alta temperatura - o lineamento de Além-Paraíba (RJ). Petrotrama de plagioclásio - Anisotropia sísmica - Reologia da litosfera continental. Tese de Livre-Docência, Universidade de São Paulo, 226 p.

Egydio-Silva M., Vauchez, A, Bascou, J., Hippertt, J. F. 2002. High temperature deformation in the neoproterozoic transpressional Ribeira Belt, southeast Brazil. Tectonophysics, 352:203-224.

Egydio-Silva M., Vauchez A, Raposo M.I.B., Bascou J. Uhlein A. 2005. Deformation regime variation in an accurate transpressional orogen (Ribeira belt, SE Brazil) imaged by anisotropy of magnetic susceptibility in granulites. $J$. Struc. Geol., 27:1750-1764.

Endo I. 1997. Regimes tectônicos do Arqueano e Proterozóico no interior da placa sanfranciscana: Quadriláte- ro Ferrifero e areas adjascentes, Minas Gerais. Tese de Doutoramento, Universidade de São Paulo, 243 p.

Fassbinder E. 1996. A unidade Água Clara no contexto do Grupo Açungui: um modelo transpressivo de colisão oblíqua no neoproterozóico paranaense. Tese de Doutoramento, Universidade de São Paulo, 207 p.

Hackpacher P. \& Godoy A.M. 1999. Vertical displacement during late-collisional escape tectonics (Brasiliano Orogeny) in the Ribeira Belt, São Paulo State, Brazil. $J$. Afric. Earth Sci., 29:25-32.

Hanmer S. \& Passchier C.W. 1991. Shear-sense indicators: a review. Geol. Surv. of Canada, Paper 90-17, 72 p.

Harland W.B. 1971. Tectonic transpression in Caledonian Spitsbergen. Geol. Mag., 108:27-42.

Harz E.H., Andresen A., Hodges K.V., Martin M.W. 2001. Syncontractional extension and exhumation of deep crustal rocks in the east Greenland Caledonides. Tectonics, 20:58-77.

Heilbron M., Valeriano C.M., Almeida J.C.H., Tupinambá M. 1991. A Megassinformal do Paraíba do Sul e sua implicação na compartimentação tectônica do setor central da Faixa Ribeira. In: SBG, Simp. Geol. Sud., 2, Atas, p. 519-527.

Heilbron M., Pedrosa-Soares A.C., Campos Neto M., Silva L.C., Trouw R.A.J., Janasi V.A. 2004. Província Mantiqueira. In: V. Mantesso-Netto, A. Bartorelli, C.D.R. Carneiro, B.B. Brito-Neves (eds.) Geologia do continente sulamericano - evolução da obra de Fernando Flávio Marques de Almeida. São Paulo, Beca, p. 203-234.

Hobbs B. E., Means B.W.D., Williams P.F. 1976. An outline of structural geology, New York, John-Wiley \& Sons, $570 \mathrm{p}$.

Holdsworth R.E \& Strachan R.A 1991. Interlinked system of ductile strike-slip and thrusting formed by Caledonian sinistral transpression in northeastern Greenland. Geology, 19:510-13.

Holdsworth R.E, Strachan R.A., Dewey J.D. 1998. Preface. In: R.E. Holdsworth, R.A. Strachan, J.F.Dewey, (eds) Continental Transpressional and Transtensional Tectonics. London, Spec. Publ. Geol. Soc., 135.

Hudleston P.J., Schultz-Ela, D.D., Southwick D.L. 1988. Transpression in an Archean greenstone belt, northern Minnesota. Can. J. Earth Sci., 25:1060-1068.

Inger S. 1998. Timing of an extensional detachment during convergent orogeny: New $\mathrm{Rb} / \mathrm{Sr}$ geochronological data from the Zanskar shear zone, northwestern Himalaya. Geology, 26:223-226.

James A.I. \& Watkinson A.J. 1994. Initiation of folding and boudinage in wrench shear and transpression. J. Struc. Geol., 16:883-893.

Jardim de Sa E.F. 1994. A Faixa Seridó (Provincia Borborema, NE do Brasil) e o seu significado geodinâmico na cadeia Brasiliana/Pan-Africana. Tese de Doutoramento, Universidade de Brasília, 803 p.

Jarrard R.D. 1986. Terrane motion by strike-slip faulting of forearc slivers. Geology, 14:780-783.

Jones R.R., Holdsworth R.E., Bailey W. 1997. Lateral extrusion in transpression zones: the importance of boundary conditions. J. Struc. Geol., 19:1201-1217.

Karniol T.R. \& Machado R. 2004. Análise geométrica e ci- 
nemática de um segmento na região do baixo Rio Doce entre Aimorés (MG) e Colatina (ES). Rev. Bras. Geoc., 34:373-382.

Leblanc D., Gleizes G., Roux L., Bouchez J.L. 1996. Variscan dextral transpression in the French Pyrenees: new data from the Pic des Trois-Seigneurs granodiorite and its country rocks. Tectonophysics, 261:331-345.

Lister G.S. \& Williams P.F. 1983. The partitioning of deformation in flowing rock masses. Tectonophysics, 92:133.

Lyberis N. \& Mamby G. 1999. Continental collision and lateral escape deformation in the lower and upper crust: An example from Caledonide Svalbard. Tectonics, 18:4063.

Machado R. \& Endo I. 1993a. A megaestrutura em flor positiva do Vale do Rio Paraíba do Sul no Rio de Janeiro e suas implicações tectônicas regionais. In: SBG, Simp. Geol. Sud., 3, Atas, p. 208-213.

Machado R. \& Endo I. 1993b. Cinturão de Cisalhamento Atlântico: um exemplo de tectônica transpressiva neoproterozóica. In: SBG, Simp. Nac. Est. Tect., 4, Atas, p. 189-191.

Machado R. 1984. Evolução geológica, análise estrutural e metamórfica da região de Vassouras e Paracambi, porção ocidental do Estado do Rio de Janeiro. Tese de Doutoramento, Universidade de São Paulo, 196 p.

Machado R. 1997. Litogeoquímica e tectônica dos granitóides neoproterozóicos do Cinturão Paraíba do Sul no Estado do Rio de Janeiro. Tese de Livre-Docência, Universidade de São Paulo, 215 p.

Machado N., Valladares C.S., Heilbron M., Valeriano C.M. 1996. U/Pb geochronology of the central Ribeira belt: implications for the evolution of brasiliano orogeny. Prec. Res., 79:347-361.

Mancktelow N.S. 1992. Neogene lateral extension during convergence in the Central Alps: Evidence from interrelated faulting and backfolding around the Simplonpass (Switzerland). Tectonophysics, 215:295-317.

Marshak S., Alkmim F., Whittington C., Pedrosa-Soares A.C. 2006. Extensional collapse in the Neoproterozoic Araçuaí orogen, eastern Brazil: a setting for reactivation of asymmetric crenulation cleavage. J. Struc. Geol., 28:129-147.

Nalini A. 1997. Caractérisation des suites magmatiques néoprotérozoïques de la région de Conselheiro Pena et Galiléia (Minas Gerais, Brésil): étude géochimique et structurales des suites Galiléia et Urucum et leur relation avec les pegmatites à élements rares associées. Tese de Doutoramento, École des Mines de Saint-Étienne e École des Mines de Paris, França, 237 p.

Passchier C. W. \& Trouw R.A.J. 1996. Microtectonics. Berlim, Springer-Verlag, $289 \mathrm{p}$.

Pêcher A. 1991. The contact between the higher Himalaya crystallines and the Tibetan sedimentary series: Miocene large-scale dextral shearing. Tectonics, 10:587-598.

Peres G.G., Alkmim F.F., Jordt-Evangelista H. 2004. The southern Araçaí belt and the Dom Silvério Group: geologic architecture and tectonic significance. An. Acad. Bras. Ciênc., 76:771-790.
Philip H., Cisternas A., Grishiam A., Gorshkov A. 1989. The Caucasus: an actual example of the initial stages of continental collision. Tectonophysics, 161:1-21.

Ratschbacher L., Frisch W., Linzer H., Merle O. 1991. Lateral extrusion in the eastern Alps, part II: Structural Analysis. Tectonics, 10:257-271.

Robin P.Y.M. \& Cruden A.R. 1994. Strain and vorticity patterns in ideally ductile transpression zones. J. Struc. Geol., 16:447-466.

Sanderson D.J. \& Marchini W.R.D. 1984. Transpression. J. Struc. Geol., 6:449-458.

Seyferth M. \& Henk A. 2004. Syn-convergent exhumation and lateral extrusion in continental collision zones - insights from three-dimensional numerical models. Tectonophysics, 382:1-29.

Silva L.C., McNaughton N.J., Armstrong R., Hartmann L.A., Fletcher I. R. 2005. The neoproterozoic Mantiqueira Province and its African connections: a zircon-based $\mathrm{U}-\mathrm{Pb}$ geochronologic subdivision for the Brasiliano/PanAfrican systems of orogens. Prec. Res., 136:203-240.

Simpson C. \& Schmid S.M. 1983. An evaluation of criteria to deduce the sense of movement in sheared rocks, Geol. Soc. Am. Bull., 94:1281-1288.

Söllner F., Lammerer B., Weber-Diffenback K. 1991. Die krustenentwiclkung nordlich von Rio de Janeiro/Brasilien. München, Münchner Geologische Hefte, v.4, 100 p.

Strachan R.A., Martin M.W., Friderichsen J.D. 2001. Evidence for contemporary yet contrasting styler of granite magmatism during extensional collapse of the northeast Greenland Caledonides. Tectonics, 20:458-473.

Tikoff B. \& Teyssier C. 1994. Strain modeling of displacement-field partitioning in transpressional orogens. Journ. Struc. Geol., 16:1575-1588.

Trompette R., Egydio-Silva M., Tommasi A., Vauchez A., Uhlein A. 1993. Amalgamação do Gondwana Ocidental no Panafricano-Brasiliano e o papel da geometria do Cráton do São Francisco na arquitetura da Faixa Ribeira. Rev.Bras. Geoc., 23:187-93.

Trouw R.A.J., Heilbron M., Ribeiro A., Paciullo F.V.P., Valeriano C.M., Almeida J.C.H., Tupinambá M., Andreis R. 2000. The central segment of the Ribeira Belt. In: U.G. Cordani, E.J. Milani, A. Thomaz Filho, D.A. Campos (eds.) Tectonic Evolution of South America, Rio de Janeiro, p.287-310.

Turner F.J. \& Weiss L.E. 1963. Structural Analysis of Metamorphic Tectonites. New York, McGraw Hill, 545 p.

Vauchez A., Tommasi A., Egydio-Silva M. 1994. Self indentation of a heterogeneous continental lithosphere. Geology, 22:967-970.

Wheeler J. \& Butler R.W.H. 1993. Evidence for extension in the western Alpine orogen: the contact between the oceanic Piemonte and overlying continental Sesia units. Earth Planet. Sci. Letters, 117:457-474.

Manuscrito ID 8203 Submetido em 20 de maio de 2007 Aceito em 15 de setembro de 2007 Sistema eletrônico de submissão. 